\title{
EFECTIVIDAD DE LOS DERECHOS COLECTIVOS \\ DE LOS PUEBLOS INDÍGENAS: EL CASO DE PERÚ Y EL ECUADOR
}

\author{
EFFECTIVENESS OF THE COLLECTIVE RIGHTS OF INDIGENOUS PEOPLES: \\ THE CASE OF PERU AND ECUADOR
}

Luis Alberto Tuaza-Castro ${ }^{1}$

\begin{abstract}
Resumen
El artículo analiza el alcance de los derechos colectivos de los pueblos indígenas en Perú y en el Ecuador. Para el efecto se analizan los casos de los conflictos mineros en la Comunidad Nativa Tres Islas del Departamento peruano Madre Dios, y la lucha de los indígenas de la parroquia Tundayme, de la provincia ecuatoriana de Zamora Chinchipe. Se considera que el Convenio 169 de la OIT y los tratados internacionales, referentes a los derechos colectivos indígenas, garantizan sus derechos al territorio y a la sana supervivencia, y constituyen los instrumentos jurídicos más importantes en la lucha frente a la minería. No obstante, la existencia de estos y otros instrumentos internacionales suscritos por Perú y el Ecuador, los derechos colectivos de los indígenas son escasamente asumidos por los Estados.
\end{abstract}

\section{Palabras clave}

Pueblos indígenas, Derechos colectivos, Minería ilegal, Tratados internacionales.

\begin{abstract}
The article analyzes the scope of the collective rights of indigenous peoples in Peru and Ecuador. For this purpose, the cases of mining conflicts in the Tres Islas Native Community of the Peruvian Department Madre Dios, and the struggle of the indigenous people of the Tundayme parish, in the Ecuadorian province of Zamora Chinchipe, are analyzed. ILO Convention 169 and international treaties, referring to collective rights, are considered to guarantee the rights to the territory and the healthy survival of indigenous people and constitute the most important legal instruments in the fight against mining. Despite the existence of these and other international instruments signed by Peru and Ecuador, Indigenous collective rights are scarcely assumed by the states.
\end{abstract}

\section{Key Words}

Indigenous peoples, Collective rights, Illegal mining, International treaties.

\footnotetext{
${ }^{1}$ Universidad Nacional de Chimborazo (Ecuador). Correo electrónico: ltuaza@unach.edu.ec.
} 


\section{Introducción}

Históricamente los pueblos indígenas en América Latina, y particularmente en Perú y en el Ecuador, han permanecido en los márgenes de los Estados (Das y Poole, 2008). Sus derechos a una vida digna, a ser ciudadanos en la diversidad cultural, a una educación propia, a la administración de justicia de acuerdo a sus costumbres y tradiciones, o a que sus territorios sean protegidos, escasamente han sido asumidos por los Estados.

Hace doscientos años, las luchas emancipatorias protagonizadas por los próceres de la independencia, provocaron la ruptura del dominio colonial europeo e instauraron las repúblicas a lo largo y ancho de la región (Borja, 2009). Sin embargo, estas luchas libertarias, lejos de buscar la emancipación de todos los integrantes de las nacientes repúblicas latinoamericanas, promovieron únicamente la ruptura de las élites criollas de la Corona española (Paz y Miño, 2009). Algunos padres de la independencia tenían deudas por impuestos a la Corona y buscaban afanosamente manejar el poder local (Hurtado, 1997); por tanto, en las campañas independentistas encontraron la oportunidad de liberarse de las deudas y asumir inmediatamente el control del poder político y económico, pero sin tomar en cuenta la libertad de todos los habitantes, especialmente los indígenas y afrodescendientes.

La historiografía tradicional exalta a los héroes criollos o blancos, pero no a "indígenas, esclavos, comerciantes, artesanos"(Hurtado, 1997, p.50), nialos afrodescendientes, tampoco a las mujeres. Cuando se establecieron las repúblicas, en las primeras constituciones, no aparecen artículos referentes a los indígenas, al contrario, la administración de estas poblaciones se delegó a la esfera de lo privado (Guerrero, 2010). La constitución ecuatoriana de 1830, artículo 68, determinaba que los curas párrocos sean nombrados "tutores y padres naturales" de la "inocente, abyecta y miserable" raza indígena. En el Perú, la primera constitución de 1823 ni siquiera menciona a los indígenas.

No obstante, en el siglo XX, tanto en Ecuador como en el Perú, surgió el propósito de incorporar a los indígenas al Estado Nación, blanco mestizo, a través de las políticas indigenistas de educación, proyectos de desarrollo, el apoyo a las organizaciones campesinas, la emisión de leyes favorables a la creación de las comunidades, la promulgación de las reformas agrarias, la modernización de zonas rurales mediante una inyección enorme de capitales extranjeros, y la colonización forzada de las regiones indias (Barre, 1983; Favre, 1998).

A finales del siglo XX, en los dos países, sus constituciones reconocieron la composición multicultural de sus ciudadanos $^{2}$, la existencia de territorios y derechos colectivos indígenas, especialmente de aquellos que ya se recogían en el Convenio 169 de la Organización Internacional del Trabajo (OIT) sobre pueblos indígenas $\mathrm{y}$ tribales, $\mathrm{y}$ en diversos tratados internacionales. Ahora bien, es válido preguntarse hasta qué punto estos reconocimientos jurídicos favorecieron a los pueblos indígenas, y en qué medida los dos Estados asumieron las orientaciones contenidas en el Convenio 169 y otros tratados internacionales que también abordan la materia. Con el propósito de analizar estas preocupaciones, en el presente artículo se plantean las siguientes preguntas ¿Cuál es el alcance de los derechos colectivos de los pueblos indígenas actualmente en el Perú y en el Ecuador? ¿En qué medida los gobiernos de los dos países observan las exhortaciones del Convenio 169 y los tratados internacionales que garantizan los derechos de los indígenas?

La reflexión consta de tres partes: de entrada, se describe los conflictos mineros a los que se enfrentan los pueblos indígenas en los dos países, en la segunda parte, se señala la importancia que tienen los derechos colectivos para los pueblos indígenas en su lucha frente al extractivismo minero y, finalmente, a manera de conclusión se estudian los procedimientos que los dos Estados observan para cumplir con las exhortaciones, tanto del Convenio 169, como de otros tratados internaciones referentes a los pueblos indígenas. Para este análisis se toman los casos de los conflictos mineros presentes en la Comunidad Nativa Tres Islas del departamento peruano de Madre de Dios y la lucha de los indígenas de la parroquia Tundayme, de la provincia ecuatoriana de Zamora Chinchipe, que aparecen en las notas de prensa, los reportajes televisivos, las denuncias judiciales de los dirigentes presentados a las cortes estatales y a la comunidad internacional, y en los trabajos secundarios sobre la minería en territorios indígenas.

\section{Los conflictos mineros y los pueblos indígenas en Perú y en Ecuador}

En estos últimos años, los pueblos indígenas de América Latina son víctimas del extractivismo minero. Sus territorios son invadidos constantemente por personas

\footnotetext{
${ }^{2}$ En el caso de Perú la Constitución de 1993, en el artículo 2 habla del derecho a la identidad de cada persona, numeral 2 del mismo artículo entre otros aspectos a no ser discriminado por razones de raza. En Ecuador, la constitución de 1998, reconoce el carácter pluricultural y multiétnico del país; por su parte, la Constitución 2008 reconoce al Estado como intercultural y plurinacional.
} 
extrañas, algunas vinculadas con mafias, que buscan hacer fortuna con la explotación del oro, el cobre y otros metales (Palacín, 2014). Es importante resaltar que la minería altera la vida de los indígenas, destruye los bosques, la flora y la fauna nativa.

Los Estados que otorgan concesiones mineras a las empresas transnacionales en los territorios indígenas, y las personas que se dedican a la minería legal e ilegal, piensan que esta actividad otorga beneficios económicos inmediatos y promueve el desarrollo de los países y de los habitantes del lugar, en los que se encuentran las minas (Palacín, 2014). Sin embargo, esto no sucede, tal como se demostrará más adelante.

Uno de los conflictos mineros que ha llamado la atención de la comunidad internacional, es el caso de la Comunidad Nativa Tres Islas de Madre de Dios. El 3 de marzo de 2016, los dirigentes de esta comunidad presentaron la solicitud de medidas cautelares a la Comisión Interamericana de Derechos Humanos (CIDH), para que la República del Perú "adopte las medidas necesarias y garantice la vida e integridad de los miembros" (CIDH, 2017, p. 1) de dicha comunidad.

La comunidad Nativa Tres Islas se encuentra asentada en la sub-cuenca del río Madre de Dios, en el distrito y provincia de Tambopata del departamento de Madre de Dios, en la región amazónica del Perú. Según los estudios de la Sociedad Peruana de Derecho Ambiental (SDA, 2020), el departamento de Madre de Dios es una de las zonas más biodiversas del planeta. Hasta los años noventa fue la región mejor preservada de la Amazonía peruana, pero el alza sin precedentes del precio internacional del oro en la primera década del dos mil, originó una fiebre extractivista de este metal precioso, que afecta gravemente al bosque nativo y a la biodiversidad. Se calcula que desde 2005 hasta 2018, se ha deforestado 50 mil hectáreas de bosque (SDA, 2020).

La extracción del oro se realiza en los ríos Tambopata, Madre de Dios y sus afluentes. Igualmente, en las tierras húmedas por medio de la explotación aurífera aluvial. Según el informe preparado por el Instituto de Investigaciones de la Amazonía peruana y del Ministerio del Ambiente (2011), al recorrer la región se puede ver árboles talados, charcos de agua contaminada con mercurio, montañas artificiales de piedra y arena, o se puede escuchar el ruido de los motores que siguen drenando los bosques. A decir de Julio Cusurichi, presidente de la Federación Nativa del Río Madre de Dios y Afluentes (FENAMAD), "en medio del bosque, los mineros ingresan a las tierras pertenecientes a las comunidades, abren caminos y talan árboles. Pueden tener permiso de uso, pero sus métodos de extracción son ilegales porque utilizan mercurio y contaminan el agua y la tierra" (Entrevistado por Diario El Comercio, 15.09.19).

Evidentemente, para la extracción del oro, los mineros invaden violentamente los territorios indígenas sin ningún tipo de permisos. La presidenta de la comunidad Tres Islas señala, "los mineros vienen a las orillas del río, instalan sus barcazas, sus motores, sin pedir permiso a nadie y abren los hoyos. Cuando alguien reclama, amenazan con pistola" (Entrevistada por Panorama Perú, 20.12.2014). De acuerdo a los reportajes de la televisión peruana, las zonas como La Pampa, km 103 de la vía interoceánica, es un territorio donde no hay presencia del Estado. En esta parte operan las mafias que violentamente invaden los territorios indígenas, introducen sus maquinarias, imponen sus negocios que van desde la venta de herramientas, combustible, cervezas, trata de personas y prostitución (Panorama Perú, 2014).

Los mineros que llegan a esta región, proceden del Puno, Cusco, Lima y de otras regiones del Perú. Son personas que no encuentran fuentes de trabajo en sus lugares de origen. Van a la selva con la esperanza de encontrar ganancias económicas altas y tener mejores condiciones de vida. En su mayoría son jóvenes reclutados por los mineros ilegales, que trabajan al margen de la ley y en conexiones con las mafias. Uno de los mineros manifiesta, "aquí en Cusco no hay nada que hacer. Si encontramos trabajo, nos pagan poco. En Madre de Dios podemos sacar el oro y con poco de suerte, en un día podemos tener 150 soles. El trabajo es duro, pero qué vamos hacer. La única manera de sacar adelante a la familia es trabajando ahí" (Entrevistado por Panorama Perú, 23.04.17).

En efecto, un minero pasa día y noche en las minas, sumergido en el agua, con poco alimento, realiza su labor en pésimas condiciones y en un ambiente de alta inseguridad. Hay dos tipos de mineros, unos los dueños de las barcazas y los motores, y otros que son empleados que trabajan para los primeros, en completa sumisión. Las labores cotidianas de los mineros consisten en: cortar árboles, excavar el suelo, introducir agua en los tubos grandes de metal y bombear hacia las plataformas diseñados con canales en la parte alta y con alfombras en el piso, sacudir las alfombras, recoger el agua con pequeñas pepas de oro en los baldes, y luego fundir los residuos que quedan en la superficie del balde con mercurio. En Madre de Dios se estima que se producen entre 16.000 a $18.000 \mathrm{~kg}$. de oro al año, y por cada kg de oro extraído se utiliza unos $2.8 \mathrm{~kg}$ de mercurio. Se calcula 
que, hasta el momento, han vertido en los ríos alrededor 3000 toneladas de mercurio (Informe, 2011, p. 15).

En la solicitud de medidas cautelares presentada por la Comunidad Nativa Tres Islas de Madre de Dios a la $\mathrm{CIDH}$, los dirigentes argumentaron que "existe la presencia probada de mercurio en los cuerpos de los miembros de la comunidad en niveles superiores a los permisibles, según informes oficiales" (CIDH, 2017, p.2). En efecto, la presencia de mercurio afecta la salud de todos los integrantes, con mayor impacto en los niños, niñas y mujeres embrazadas, contamina las aguas y la tierra. El mercurio vaporizado se condensa y cae al suelo o al agua, y por reacción de bacterias de los lodos se transforma en metilmercurio, un compuesto muy tóxico. El metilmercurio es consumido por los peces (Informe, 2011), los cuales sirven de alimento de las 125 familias de Tres Islas. Según los estudios de la Dirección Regional de Salud del Gobierno Regional de Madre de Dios y de la Universidad de Duke (2014), concluyen que la población contiene alto grado de mercurio en la sangre. Esto provoca cáncer, problemas en la piel, el aborto, las deformaciones de los fetos, dolores de cabeza y otras enfermedades cardiovasculares.

En Ecuador, el conflicto minero entre la empresa Ecuacorriente (ECSA), subsidiaria del consorcio chino CRCC-Tongguan, y los indígenas de la parroquia Tundayme, atrae la atención de la prensa, de las organizaciones no gubernamentales dedicadas a la preservación del medio ambiente y de la comunidad internacional (Bermúdez, 2019). La parroquia Tundayme, pertenece al cantón Pangui de la provincia amazónica de Zamora Chinchipe, situada en el sur este del Ecuador (PDOTT, 2015).

Tundayme cuenta con 854 habitantes, la mayoría de ellos pertenecientes a la nacionalidad shuar, y en menor número a indígenas procedentes de las provincias serranas de Loja y Cañar, asimismo, a mestizos oriundos de la provincia del Azuay (PDOTT, 2015). La localidad fue fundada en 1951, como comunidad dependiente de la parroquia Los Encuentros y elevada a parroquia en 1994. Tundayme está conformada por las comunidades indígenas de Cascome, Churowia, Numpai San Carlos, la Comunidad Ancestral de la Federación Shuar, Yanua kim y San Marcos (PDOTT, 2015). Esta última comunidad desapareció, a consecuencia de los desalojos por parte del gobierno, efectuado en 2014, a fin de permitir la construcción de la planta procesadora del Proyecto Minero Mirador, propiedad de la empresa minera ECSA.

Las primeras exploraciones de la empresa minera a la región, según recuerdan los habitantes, "empezó en 2004, ya desde ese año, la empresa minera vino comprando las tierras individualmente a los moradores de la comunidad San Marcos, haciéndoles creer que les pagaría bien por las tierras, les reubicaría en buenas propiedades cerca de Pangui y les daría buenas oportunidades laborales" (Entrevistados por Plan V, 12.02.19).

El 5 de marzo de 2012, el Estado ecuatoriano, a través del Ministerio de Recursos Naturales No Renovables, suscribió el contrato de explotación minera a gran escala con la empresa minera ECSA, por un plazo de 30 años (Pérez, 2019), en territorios correspondientes a los pueblos indígenas. El contrato concede a la dicha empresa un área de 2.895 hectáreas, que corresponde a la zona denominada Mirador 1 para ejecutar las operaciones mineras. Además, autoriza realizar actividades relacionadas en un área de 2.815 hectáreas y un área adicional de 510 hectáreas denominadas área de protección (Pérez, 2019).

Según Fernando Benalcázar, viceministro de minas, "las ventajas de la mina son claras: 3.000 empleos directos y 10.000 indirectos, US \$211 millones entre regalías anticipadas e impuestos, ingresos totales en el orden de US $\$ 5.500$ millones para el gobierno y $60 \%$ de las regalías invertidas por ley a nivel local y provincial. Además, asociarse con una empresa china les da acceso garantizado al mayor comprador de cobre del mundo" (Plan V, 2019). La mina, según ECSA, producirá 3,18 millones de toneladas de cobre, además de 3,39 millones de onzas de oro y 27,11 millones de toneladas de plata" (ECSA, 2019). A decir de la empresa, la explotación minera cumple con todos los estándares internacionales, sociales y ambientales, y, para el año 2020 aportará el 4\% del PIB nacional (ECSA, 2019).

La empresa ha invertido 1,4 millones de dólares en la infraestructura de procesamiento de cobre. Igualmente sostiene que ha invertido en la construcción de la escuela del milenio, la edificación del puente sobre el río Zamora, la vía Chuchunbetsa - Mirador, pavimento en las calles de Tundayme y Chuchunbetsa; ha otorga becas a los jóvenes de escasos recursos, proporciona la enseñanza del idioma chino mandarín y la capacitación ambiental en las instituciones educativas de la zona; entrega de máquinas a las mujeres, proyectos de piscicultura. Considera que se toma en serio el manejo del impacto ambiental, volviendo a cultivar árboles en la zona intervenida (ECSA, 2019).

No obstante, lejos de las bondades anteriormente descritas, los estudios y los testimonios de los dirigentes indígenas desmienten esta realidad, por cuanto que oculta la tragedia humana y ambiental. Las comunidades 
nunca fueron consultadas, tal como exige la constitución, el Convenio 169 y los tratados internacionales. Los miembros de la comunidad San Marcos, fueron desalojados violentamente de su territorio. El 16 de diciembre del 2015, entre las dos y seis de la mañana con presencia policial, funcionarios de la comisaría, fiscales y trabajadores de ECSA ejecutaron los desalojos, destruyeron la escuela, la iglesia y las casas utilizando maquinaria pesada. "Fuimos desalojados violentamente, nuestras casas fueron tumbados con maquinaria, nunca pagaron las indemnizaciones, no fuimos reubicados. De un momento para el otro, perdimos nuestras casas, las tierras, los animales, el pequeño patrimonio obtenido con mucho trabajo", señala José Sánchez, presidente de la comunidad Cascomi (Entrevistado por Plan V, 19.02.19). De acuerdo al testimonio de este mismo dirigente, "las personas que perdieron sus tierras y casas, ahora viven en Pangui, en Gualaquiza arrendando un cuarto, sin trabajo, sin parcelas y sin animales. Por la minería, perdieron todo" (Entrevistado por Plan V, 19.02.19).

Según las versiones oficiales de ECSA, hay un acuerdo conjunto con los antiguos propietarios de las tierras donde está situada la minería a gran escala, la población de Tundayme habría mejorado sus condiciones de vida, tendría acceso a nuevos recursos, la empresa observa la responsabilidad con la sociedad (ECSA, 2019). Según la versión de José Sánchez, "no todos están de acuerdo con ECSA, pocas personas respaldan la minería y la presencia de esta empresa. La mayoría queremos nuestras tierras y un ambiente vital sano. A causa de la minería se ha roto el tejido comunitario" (Entrevistado por Plan V, 19.02.19).

Los conflictos entre ECSA y los pueblos indígenas de Tundayme, a más de los actos violentos de desalojo, el aniquilamiento de las formas ancestrales de vida, la ruptura del tejido organizativo, llegó a cobrar la vida del dirigente José Tendetza. El 3 de diciembre de 2014, su cuerpo sin vida fue encontrado atado con una cuerda en el río Chucumbletza. El 28 de noviembre del mismo año, él habría salido de su casa a participar en una reunión de la Asociación Shuar de Bomboiza, pero no llegó. El objetivo de esta reunión fue la preparación sobre los impactos de la minería en el medio ambiente, que planeaba llevar a la cumbre de los pueblos, un evento paralelo a la conferencia de las partes (COP 20), que se realizó en Lima, a fines del 2014 (Carvajal, 2016).

Por estos actos cometidos contra las comunidades y sus dirigentes, en contraste a las versiones optimistas del gobierno, de ECSA y de algunos indígenas que trabajan en la empresa, la mayoría de los indígenas de Tundayme desconfían de la empresa y de la actividad minera. Ven en la minería el inicio de la vida precaria, por cuanto ahora ya no tienen agua limpia ni acceso a fuentes hídricas, los ríos Wawayme, Tundayme y Kime están contaminados con material pétreo y con los metales pesados que son nocivos para la salud (Pérez, 2019). El gran problema ambiental, según los dirigentes consultados por Plan V, es el tratamiento de los relaves, los depósitos de tierra o escombreras que saldrán de las 60 mil toneladas de piedras al día, la contaminación de las aguas y la deforestación en una zona de montañas de poca consistencia pétrea (Plan V, 2019).

La empresa asegura que cumple con todos los requisitos ambientales (ECSA, 2019), sin embargo, las organizaciones ecologistas, los indígenas y los críticos del proyecto sostienen que los informes y autorizaciones ambientales no han sido expuestos públicamente ni por la empresa ni por el Ministerio del Ambiente (Pérez, 2019). La destrucción medio ambiental provocada por ECSA, ocasiona la desaparición de cientos de especies animales que se quedan sin su hábitat, la flora más rica, con más de 202030 especies, entre ellas 65 tipos de orquídeas, y una de las pocas plantas carnívoras del Ecuador (Palma, 2017).

\section{Los derechos colectivos de los pueblos indigenas y el extractivismo minero}

Desde los tiempos de la colonia y aún establecidas las repúblicas, los pueblos indígenas se encuentran afectados por las decisiones desacertadas de los Estados (Das y Poole, 2008). Sus demandas son escasamente acogidas; sus territorios frecuentemente son expuestos a los intereses de mineros, madereros, buscadores de caucho, o la industria petrolera o farmacéutica (Paz, 2018). En muchos casos, los Estados que tienen territorios amazónicos delegaron la administración de estos lugares a las congregaciones religiosas católicas, a los colonos o sencillamente les abandonaron a su suerte (Muratorio, 1998). Esto dio paso al saqueo, al desalojo de los indígenas de sus tierras, la introducción de nuevas enfermedades, la destrucción de los bosques y la biodiversidad, el genocidio y el etnocidio, $\mathrm{y}$ a todo acto de ilegalidad cometido por las personas foráneas, las mafias y las empresas transnacionales (Hernández, 2009).

En caso de existir la preocupación de los Estados por ejercer la administración territorial y poblacional de los pueblos indígenas, otorgar seguridad jurídica, militar y policial, ejecutar políticas públicas, en cuanto construcción de vías, puentes, escuelas y centros de salud, estos se dan, bajo la lógica económica de recaudar impuestos, regalías y de posibilitar que empresas trasnacionales vinculadas con los Estados, puedan operar 
libremente en los territorios indígenas. Según Fernández, en lo referente a la minería "es frecuente encontrar una comunión de intereses entre el Estado y las empresas, pues ambos actores tienen interés explícito en el desarrollo de la actividad extractiva" (Fernández, 2018, p.146).

Esta comunión de intereses se expresa, estructuralmente, de diversos modos. "Uno de ellos es la unidad de narrativas y semánticas que ambos actores elaboran y pretenden comunicar a la sociedad" (Fernández, 2018, p. 146). Otra de las estrategias es la de "inscribir en la opinión pública la imagen de territorios vacíos o sub-habitados" (Fernández, 2018 , p. 146), con una riqueza de bienes naturales que podrían ser ocupados económicamente. También, la otra táctica es demostrar que los territorios indígenas son "vacíos" o "socialmente vaciables" (Svampa, 2008, p. 8), que pueden ser utilizados para "la expansión de nuevos emprendimientos productivos" (Svampa, 2008, p. 8), espacios en que las grandes empresas podrían ejercer el control y generar ganancias económicas.

En los procesos de legitimación de la presencia de una empresa en territorios indígenas, Composto y Navarro (2014), indican que los Estados se valen del marco institucional, a través de los cuales establecen normas, hacen concesión de derechos, y argumentan que la minería obedece al interés nacional. Frente a la resistencia que oponen los indígenas, hacen negociaciones, coaptan a dirigentes, ejercen el disciplinamiento; y si estos no funcionan, generan la conflictividad directa, reprimen protestas, criminalizan la lucha y militarizan los territorios.

La resistencia de los pueblos indígenas es considerada por las empresas y los Estados como "actitudes contrarias al progreso y desarrollo" (Fernández, 2018, p. 147), que margina de las dinámicas sociales y la realidad sociocultural, la mundialización de cada territorio en lo que Leff denomina "el orden económico ecológico globalizado (Leff, 2007: 18). En el intento de desarticular la movilización social indígena, las empresas y los Estados generan "un escenario de, divergencias entre comunidades que defienden el derecho al control sobre el territorio y aquellas otras que acogen las perspectivas de desarrollo productivo que el emprendimiento extractivo sugiere" (Fernández, 2018, p.147).

En las situaciones señaladas en los acápites anteriores, los pueblos indígenas apelan a los tratados y convenios internacionales que reconocen sus derechos a la defensa de sus territorios, la diversidad cultural, la educación, la resolución de conflictos y al desarrollo. El principal cuerpo legal internacional que reconoce los derechos de los pueblos indígenas es el Convenio 169 de la Organización
Internacional del Trabajo (OIT) de 1989, ratificado por 15 países de América Latina, entre estos Perú y Ecuador. Este convenio establece que los pueblos indígenas tienen el derecho de mantener $y$ fortalecer sus culturas, formas de vida e instituciones propias, y su derecho a participar de manera efectiva en las decisiones que les afectan; "tienen derecho a decidir sus propias prioridades en lo referente al proceso de desarrollo, en la medida en que éste afecte sus vidas, creencias, instituciones y bienestar espiritual y a las tierras que ocupan o utilizan de alguna manera, y de controlar, en la medida de lo posible, su propio desarrollo económico, social y cultural" (Artículos 3 -10).

Frente a la minería, el convenio contempla que en el "caso de que pertenezca al Estado la propiedad de los minerales o de los recursos del subsuelo, o tenga derechos sobre otros recursos existentes en las tierras, los gobiernos deberán establecer o mantener procedimientos con miras a consultar a los pueblos interesados, a fin de determinar si los intereses de esos pueblos serían perjudicados, y en qué medida, ellos autorizan la ejecución de cualquier programa de prospección o explotación de los recursos existentes en sus tierras" (Artículo, 14).

Similar al Convenio 169, en el marco jurídico internacional que vela por los derechos de los pueblos indígenas, está la Declaración sobre los Derechos de los Pueblos Indígenas de Naciones Unidas (2007). Este documento, señala que los pueblos indígenas "no serán desplazados por la fuerza de sus tierras o territorios. No se procederá a ningún traslado sin el consentimiento libre, previo e informado" (Artículo 10). En el Artículo 19 indica que "los Estados celebrarán consultas y cooperarán de buena fe con los pueblos indígenas interesados por medio de sus instituciones representativas antes de adoptar y aplicar medidas legislativas o administrativas que los afecten, a fin de obtener su consentimiento libre, previo e informado". En la perspectiva ambiental, la declaración argumenta que "los pueblos indígenas tienen derecho a la conservación y protección del medio ambiente y de la capacidad productiva de sus tierras o territorios y recursos" (Artículo 29, 1).

En Perú y Ecuador, los pueblos indígenas, frente a los problemas ocasionados por la minería, sean estos legales o ilegales, han apelado a los derechos colectivos reconocidos por la comunidad internacional, en los documentos ya citados. Tanto la directiva de la Comunidad Nativa Tres Islas, como los dirigentes indígenas de Tundayme, demandaron a sus Estados ante las cortes nacionales y a la CIDH, argumentando que estos no toman en cuentan los derechos reconocidos por el Convenio 169 y la Declaración sobre los Derechos de los Pueblos Indígenas de Naciones Unidas, al momento de autorizar 
la minería en sus territorios. En ambos casos, consideran que los Estados no han procedido a realizar la consulta previa, libre y consentida, sino que, al margen de las comunidades, permiten la entrada arbitraria de personas foráneas y empresas extractivistas a sus territorios, poniendo en riesgo las vidas humanas, sus animales, sus cultivos y la biodiversidad.

Para apelar a los derechos colectivos contemplados en los convenios y tratados internacionales, y reconocidos por los Estados en sus constituciones, los indígenas tanto de la Comunidad Nativa Tres Islas y los indígenas de Tundayme acudieron a su identidad étnica (Wade, 2000), que busca por un lado "preservar la dignidad de la persona y la integridad del grupo" (Muratorio, 1998, p. 319), y, por otro lado, tiene que ver con el tema del "poder y la resistencia" (Muratorio, 1998, p. 321).

Así, la identidad indígena se relaciona con el territorio, el pasado histórico, y la cultura que los distingue de colonos, misioneros, patrones, mineros y empresas transnacionales, y les permite expresar sus derechos legítimos sobre sus territorios, la flora, la fauna, los espíritus y las fuentes de agua (Muratorio, 1998) que son alterados por los intrusos.

Los dirigentes de la comunidad nativa Tres Islas, en su solicitud de medidas cautelares a la $\mathrm{CIDH}$, argumentan ser "descendientes de los pueblos Shipibo y Ese'eja, de las familias lingüísticas Pano y Tacana (...), con reconocimiento oficial del Estado y con título de propiedad de su territorio de 1994, el cual abarcaría 31,423 Has 71 metros cuadrados" (CIDH, 2017, p. 2). No obstante, sostienen que sus territorios son invadidos por los mineros ilegales. También indican que el Estado peruano ha otorgado concesiones mineras en tierras que no les corresponden y esta situación está acabando con su hábitat, la salud de sus habitantes, especialmente de niñas, niños y mujeres, quienes son expuestos al mercurio que está en los ríos, en los peces, en la tierra, en sus huertos y animales. Piden respeto al Estado peruano, a sus derechos reconocidos por los convenios internacionales, la inmediata atención sanitaria, la seguridad y la salvaguarda de sus territorios. Los integrantes de la comunidad rechazan la minería, desean vivir en armonía con la naturaleza, tal como lo hacían sus ancestros.

Los indígenas de Tundayme, apelan igualmente a la identidad indígena a la hora de presentar sus demandas en las cortes del Ecuador. Particularmente, los indígenas de la nacionalidad shwar, señalan: "nosotros somos dueños de estos territorios, desde el tiempo de nuestros ancestros. De esta tierra hemos vivido, tenemos las chakras $^{3}$. No queremos metales, ni desarrollo. Queremos el canto de las ranas y de los pájaros, tierras buenas con frutos y animales" (Entrevistados por Plan V, 2016). El 7 de julio de 2017, en Lima, los dirigentes indígenas de Tundayme y de San Carlos Panantza, presentaron a $\mathrm{CIDH}$, la denuncia en contra del Estado y del gobierno ecuatoriano, porque este vulnera sus derechos al aprobar proyectos mineros que provocan su desplazamiento forzoso, sin haberles consultado previamente, tal como establece la constitución y los tratados internacionales (CIDH, 2017).

\section{Conclusiones}

En el Perú y en el Ecuador, los pueblos indígenas están gravemente afectados por la minería. En el primer caso, existe el abandono de las poblaciones indígenas por parte del Estado. Consecuentemente, la actividad minera funciona en el ámbito de la ilegalidad, haciendo que los indígenas estén expuestos a las mafias y a las enfermedades generadas por el mercurio y otros metales pesados, y promoviendo que sus territorios, sus bosques, su flora y fauna están siendo aniquilados.

En Ecuador la minería es legal. El Estado ha otorgado la concesión minera a favor de ECSA, con el propósito de obtener regalías y promover el desarrollo económico de la región y del país, pero se oculta la tragedia humana y ambiental que las concesiones mineras y el establecimiento de la minería a gran escala está ocasionando: familias destruidas, sin tierras ni casas, la muerte de uno de sus dirigentes, la destrucción de los bosques, la contaminación de los ríos y la pobreza. El gobierno y ECSA están convencidos que vendrán nuevos días, que los habitantes del lugar serán los primeros beneficiarios de las regalías, que el país saldrá del subdesarrollo. Pero para los indígenas es la destrucción total de su hábitat, su historia, su cultura y su futuro (Plan V, 2019).

En Perú y Ecuador, los derechos colectivos de los pueblos indígenas contemplados en el Convenio 169 y los tratados internacionales han sido ratificados. En el caso ecuatoriano, la constitución de 1998 y la constitución 2008 contemplan el reconocimiento de los derechos colectivos de pueblos y nacionalidades indígenas (Chuji, Berraondo y Dávalos 2009). La constitución 2008, habla de los derechos de la naturaleza, y en el artículo 57 , numeral 4, al mencionar los territorios, señala que los pueblos indígenas tienen el derecho de "conservar la propiedad imprescriptible de sus tierras comunitarias, que serán inalienables, inembargables e indivisibles".

\footnotetext{
${ }^{3}$ Parcelas o huertos.
} 
Más adelante en el numeral 6, habla del derecho de "participar en el uso, usufructo, administración y conservación de los recursos naturales que se hallen en sus tierras". En el numeral 7 se establece el derecho de los pueblos y nacionalidades indígenas a ser consultados previa, libre e informadamente "sobre los planes y programas de prospección, y comercialización de recursos no renovables que se encuentren en sus tierras y que puedan afectarles ambiental o culturalmente; participar en los beneficios que esos proyectos reporten y recibir indemnizaciones por los perjuicios sociales, culturales y ambientales que les causen. La consulta que deban realizar las autoridades competentes será obligatoria y oportuna”. Sin embargo, en la práctica, ni en Perú ni en Ecuador se toman con seriedad los derechos colectivos sobre territorio y minería.

En la Comunidad Nativa Tres Islas, el Estado peruano concede las concesiones mineras a personas foráneas, sin realizar la consulta previa, libre e informada (REPAM, 2016) descuida la salud de sus habitantes, no asume el control sobre la minería ilegal que afecta vastos territorios y que contamina los ríos (CIDH, 2017). Cuando los dirigentes de esta comunidad solicitan las medidas cautelares a la CIDH, apelando a los derechos colectivos en lo referente al respeto del territorio ancestral, la consulta previa libre e informada, la respuesta de los funcionarios del gobierno peruano es: "los miembros de esta comunidad ya no son indígenas, no tienen una organización social sólida. Que detrás de los indígenas están los activistas ambientales" (Entrevistados por IIDS, 2015). En contraste, los integrantes de la comunidad se definen como nativos y afirman que cuentan con derechos reconocidos por la comunidad internacional y del mismo Estado peruano. Luego de varios años de lucha contra el Estado y los mineros, el 12 de marzo de 2019, lograron que la Corte Superior de Justicia de Madre de Dios, reconozca la autonomía territorial, y ordene el cese inmediato de la actividad minera y de las concesiones otorgadas para esta actividad en su territorio (SERVINDI, 2019).

En el caso de las comunidades indígenas de Tundayme, igualmente, el gobierno no realizó la consulta previa, libre e informada a las comunidades, argumentando que el Estado es el dueño del subsuelo y que los que defienden los territorios no son propiamente indígenas (Plan V, 2019). Similar a los funcionarios peruanos, ECSA y el Ministerio de Recursos Naturales no Renovables de Ecuador, consideran que detrás de los indígenas que se resisten a la minería a gran escala, defendiendo sus territorios son motivados por ambientalistas, organizaciones no gubernamentales y personas opositoras al gobierno (Plan V, 2019). Este tipo de consideraciones, niegan toda iniciativa de defensa, de organización y de toda capacidad de agencialidad que tienen los indígenas. En los imaginarios estatales se sigue reproduciendo la imagen de los indígenas menores de edad (Adorno, 1988), menesterosos de la tutoría de los blanco - mestizos y que fácilmente pueden ser manipulados, sin reconocer que la minería es una bomba de tiempo que provoca destrucción de la vida de los indígenas y coloca en riesgo el futuro de la humanidad (BBC, 2017).

Los indígenas afectados por la minería, en Perú y Ecuador, respaldan sus demandas a los Estados en los derechos colectivos contemplados en el Convenio 169 y en los tratados internacionales. Reconocen el valor que tienen estos ordenamientos jurídicos para la defensa de sus territorios, su identidad cultural, sus modelos de desarrollo y de autogestión. Las luchas de los indígenas en defensa de sus territorios, sustentados en los mencionados cuerpos jurídicos, ha despertado el respaldo de la comunidad internacional, de las organizaciones ambientales y de la academia. En efecto, en Perú y Ecuador, los indígenas reciben el apoyo de la $\mathrm{CIDH}$, de diversas organizaciones de defensa medio ambiental y de los derechos humanos, y de las universidades, organismos que se han convertido en sus aliados estratégicos (Bretón, 2012). Sin el respaldo de estas organizaciones de la sociedad civil, la voz de los indígenas raras veces sería escuchada por los Estados y por la comunidad internacional.

En los conflictos mineros entre los Estados y los pueblos indígenas, aparecen los choques frontales en las visiones sobre la economía, el cuidado ambiental y el desarrollo. A los Estados peruano y ecuatoriano, a los mineros ilegales, a las empresas dedicadas a la extracción minera, les interesa únicamente las ganancias económicas (Svampa, 2016). La retórica generalizada es que con la minería se aumentan las regalías, el producto interno bruto, el país y las poblaciones cercanas a las minas obtienen beneficios económicos.

Pero esto no es real. Las empresas y las élites económicas obtienen mayores ventajas. En Perú y Ecuador existen zonas donde se ha realizado la explotación petrolera y de extracción minera, pero no han progresado económicamente, los indígenas continúan hundidos en la pobreza. Los Estados y las empresas mineras han pretendido aliviar la miseria entregando dádivas a la población y ofreciendo trabajos a su gente. Para los pueblos indígenas, más allá de la ganancia económica es necesario salvar y conservar los bosques y todo el medio ambiente (Gudynas, 2004). "No queremos la minería, esto es muerte, atraso y miseria" son las voces de los indígenas (Entrevistados, Plan V). En los imaginarios indígenas, la selva y la naturaleza en sí, no son únicamente recursos naturales, es la vida misma, la Pachamama, la madre 
naturaleza que exige de sus hijos la relación existencial armoniosa y amorosa (Sínodo de la Amazonía, 2019).

Por parte de los pueblos indígenas, existe la conciencia clara de que la minería no soluciona los problemas de la pobreza. Al contrario, ocasiona miseria, trae enfermedades, obliga a abandonar sus tierras y sus comunidades. Según el informe anual del Banco Mundial (2017) y el informe de la CEPAL (2016), los pueblos indígenas siguen siendo en la región, poblaciones con altos niveles de pobreza y necesidades básicas insatisfechas, ocasionadas, precisamente por el abandono de los Estados y la destrucción del medio ambiente. Esto trae como consecuencia que, de los 42 millones de indígenas de América Latina, el 53,4\% vivan en las ciudades. En las grandes urbes, los indígenas llevan la peor parte. A menudo viven en áreas que son menos seguras, menos higiénicas y más propensas a los desastres naturales, en comparación con residentes no indígenas (BM, 2017; CEPAL, 2016).

Se evidencia también que en estos últimos años en Perú y Ecuador se ha intensificado la lucha de los pueblos indígenas por la salvaguarda de sus territorios, los páramos y las selvas, la defensa del agua frente a empresas mineras y eléctricas. Sin embargo, sus luchas son consideradas actos de "terrorismo y de sabotaje" (Lander y Ospina, 2012). Se criminaliza la lucha social, se persigue a líderes indígenas, se promueven la violencia, que se expresa en desalojos forzados y en ciertos casos en asesinatos de los dirigentes (Plan V, 2019). Pero utilizan también la estrategia de desarticular la lucha social indígena por medio de sobornos, la entrega de ayudas y el establecimiento de favoritismos al interior de las comunidades. Así, aparecen personas que defienden a los mineros ilegales y a las empresas mineras, a cambio de recibir favores, desautorizando a los dirigentes y a otros integrantes de la comunidad que no ven beneficios en la minería.

De este modo, no son suficientes los tratados y convenios internacionales que reconocen los derechos colectivos, ni que las constituciones nacionales contemplen los derechos colectivos de pueblos y nacionalidades indígenas, se requiere de la voluntad política de los Estados que, al margen de toda visión paternalista, reconozcan los derechos de los pueblos indígenas, cumplan con las orientaciones dadas por los convenios y tratados internacionales, que vean a los indígenas como ciudadanos con todos los derechos, que reconozcan su aporte al desarrollo de los países, que promuevan la resolución de sus conflictos desde un proceso de aprendizaje y apertura a la otredad cultural.

\section{Referencias}

1. Adorno, R. (1988). El sujeto colonial y la construcción cultural de la alteridad. Revista de Crítica Literaria latinoamericana, 14(28), 55-68.

2. Banco Mundial. (2017). Informe anual 2017. Documento electrónico disponible en http:// documentos.bancomundial.org/curated/ es/832861507546767863/pdf/120298-WBAR-v1PUBLIC-SPANISH.pdf.

3. BBC. (2017). "Es peligroso defender la vida y el territorio". En BBC noticias, edición 31 de enero.

4. Barre, M. (1983). Ideologías indigenistas y movimientos indios. México: Siglo XXI.

5. Bermúdez, A. (2019). Los indígenas del Cóndor ecuatoriano no quieren minas de cobre. Disponible en: $\quad$ https://dialogochino.net/es/actividadesextractivas-es/28120-los-indigenas-del-condorecuatoriano-no-quieren-cobre/.

6. Borja, J. (2009). El entorno internacional en la independencia de América. Revista Afese, 51, 13 31.

7. Bretón, V. (2012). Toacazo en los Andes equinocciales tras la reforma agraria. Quito: FLACSO y Abya Yala.

8. Bretón, V. (2001). Cooperación al desarrollo y demandas étnicas en los Andes ecuatorianos. Quito: FLACSO.

9. Carvajal, A. (2016). La familia de José Tendetza apelará el fallo que absuelve a dos sospechosos. Disponible en: https://www.elcomercio.com/ actualidad/familia-tendetza-apelara-fallo-muerte. $\underline{\mathrm{html}}$.

10. Chuji, M., Berraondo, M. y Dávalos, P. (2009). Derechos colectivos de los pueblos y nacionalidades: evaluación de una década 1998 - 2008. Quito: IWGIA.

11. CIDH. (2017). Comisión Interamericana de Derechos Humanas, resolución 38/17, medida 
cautelar n. 113-16, Comunidad Nativa "Tres Islas" de Madre de Dios respecto de Perú.

12. Comisión Económica para América Latina y el Caribe. (2016). Estudio económico de América Latina y el Caribe: la Agenda 2030 para el Desarrollo Sostenible y los desafíos de financiamiento para el desarrollo. Documento electrónico disponible en: $\quad$ https://repositorio.cepal.org/bitstream/ handle/11362/40326/86/S1600799 es.pdf.

13. Composto, C., Navarro, M. (2014). Claves de lectura para comprender el despojo y las luchas por los bienes comunes naturales en América Latina. En C. Composto y M. L. Navarro (comps.), Territorios en disputa. Despojo capitalista, luchas en defensa de los bienes comunes naturales y alternativas en Territorios y recursos naturales emancipatorias para América Latina. Ciudad de México: Bajo Tierra Ediciones, pp. 33-74.

14. Das, V., y Poole, D. (2008). El Estado y sus márgenes. Etnografías comparadas. Revista Académica de Relaciones Internacionales, 8, 1-39.

15. Dirección Regional de Salud del Gobierno Regional de Madre de Dios y Universidad de Duke. (2014). Exposición a Enfermedades Emergentes y Metales Pesados en la Cuenca del Rio Madre de Dios. Disponible en: http://dge.gob.pe/portal/Asis/ indreg/asis madrededios.pdf.

16. ECSA. (2019). Proyecto Minero Mirador-Pangui Zamora Chinchipe. Disponible en: https://www. youtube.com/watch?v=r-Vr5ZzjQq0.

17. Favre, H. (1998). El indigenismo. México: FCE.

18. Fernández, L. (2018). Minería y derechos de los pueblos indígenas en América Latina. La disputa por el territorio en Raposa Serra do Sol (Tesis doctoral). Madrid: Universidad Complutense de Madrid.

19. Gobierno Autónomo Descentralizado de la Parroquia Tundayme. (2015). Plan de Ordenamiento Territorial de la Parroquia de Tundayme (PDOTT) $2014-2019$.

20. Gudynas, E. (2004). Ecología, economía y ética de desarrollo sostenible. Montevideo: Ediciones Coscoroba.
21. Guerrero, A. (2010). Administración de poblaciones, ventriloquía y transescritura. Quito: FLACSO, Instituto de Estudios Peruanos.

22. Hernández, J. (2009). Las empresas transnacionales frente a los derechos humanos: historia de una asimetría normativa. De la responsabilidad social corporativa a las redes contrahegemónicas transnacionales. Madrid: HEGEA y OMAL.

23. Hurtado, O. (1997). El poder político en el Ecuador. Quito. Editorial Planeta.

24. IIDS. (2015). La comunidad nativa Tres Islas y su lucha por la libre determinación. Disponible en: http://derechoysociedad.org/IIDS/Noticias/2015/ Nota de Prensa 19-2015.pdf.

25. Instituto de Investigaciones de la Amazonía Peruana y del Ministerio del Ambiente. (2011). Minería aurífera en Madre de Dios y contaminación con mercurio: una bomba de tiempo. Lima: Editorial Super Gráfica E.I.R.L.

26. Lander, R., Ospina, P. (2012). Movimiento indígena y revolución ciudadana en el Ecuador. Cuestiones políticas, 28 (48), 13-50.

27. Leff, E. (2007). Complejidad, racionalidad ambiental y diálogo de saberes. Desenvolvimento $e$ Meio Ambiente, 16, 11-17.

28. Muratorio, B. (1998). Rucu yaya Alonso y la historia social y económica del Alto Napo 1850 - 1950. Quito: Abya Yala.

29. Organización Internacional de Trabajo (2014). Convenio número 169 de la OIT sobre pueblos indígenas y tribales. Lima: OIT, Oficina Regional para América Latina y el Caribe.

30. Organización de las Naciones Unidas. (2013). La Declaración de las Naciones Unidas sobre los derechos de los pueblos indígenas (2007). Ginebra: Oficina de Alto Comisionado de las Naciones Unidas para los Derechos Humanos.

31. Palma, J. (2017). Ecuador: comunidades denuncian malas prácticas ambientales del Proyecto Minero Mirador. Disponible en https://es.mongabay. com/2017/04/ecuador-comunidades-denuncian- 
malas-practicas-ambientales-del-proyectominero-mirador/

32. Panorama Perú. (2014). Informales sin freno: devastación en la selva de Madre de Dios. Disponible en: https://www.youtube.com/ watch? $\mathrm{v}=\mathrm{c} 5 \mathrm{aVskUKPSA \& \textrm {t } = 1 4 0 \mathrm { s }}$

33. Palacín, M. (2014). Impacto de la minería sobre los derechos de los pueblos indígenas. Revista América Latina en Movimiento. Disponible en: https://www. alainet.org/es/active/71629.

34. Paz, A. (2018). La deforestación del proyecto minero Mirador en el sur de la Amazonía del Ecuador. Disponible en: https://es.mongabay.com/2018/08/ la-deforestacion-del-proyecto-minero-miradoren-el-sur-de-la-amazonia-de-ecuador/

35. Paz y Miño, J. (2009). El constitucionalismo en el proceso de la independencia del Ecuador. Revista Afese, 51, 33-43.

36. Pérez, A. (2019). Cordillera minada: la paradoja de la riqueza del Cóndor. Disponible en: https://www. vistazo.com/seccion/pais/actualidad-nacional/ cordillera-minada-la-paradoja-de-la-riqueza-delcondor.

37. Plan V. (2019). "La otra historia del Mirador". Disponible en: https://www.planv.com.ec/ investigacion/investigacion/la-otra-historiamirador.

38. Red Eclesial Panamazónica. (2016). Informe Regional de vulneración de los Derechos Humanos en la Panamazonía.

39. República del Ecuador. Constitución 1830.

40. SERVINDI. (2019) ¿Cómo afecta la minería ilegal en Madre de Dios?. Disponible en: https://www. servindi.org/actualidad-noticias/19/09/2019/ como-afecta-la-mineria-ilegal-en-madre-de-dios.

41. Sínodo de la Amazonía. (2019). Asamblea especial para la región panamazónica. Amazonía: nuevos caminos para la iglesia y para una nueva ecología integral. Disponible en: http://www. sinodoamazonico.va/content/sinodoamazonico/ es/documentos/documento-final-de-la-asambleaespecial-del-sinodo-de-los-obispo.html.
42. Sociedad Peruana de Derecho Ambiental (SPD). (2020). Minería ilegal en Madre de Dios: operación mercurio 2019, el baile de los que faltan. Disponible en https://www.actualidadambiental.pe/tag/ madre-de-dios/

43. Svampa, M (2016). Debates latinoamericanos: indianismo, desarrollo, dependencia y populismo. Buenos Aires: EDHASA.

44. Svampa, Maristella (2008). La disputa por el desarrollo: territorio, movimientos de carácter socioambiental y discursos dominantes. Movimientos sociales y poder político. Buenos Aires: Siglo XXI.

45. Wade, P. (2000). Raza y etnicidad en Latinoamérica. Quito: Abya Yala. 